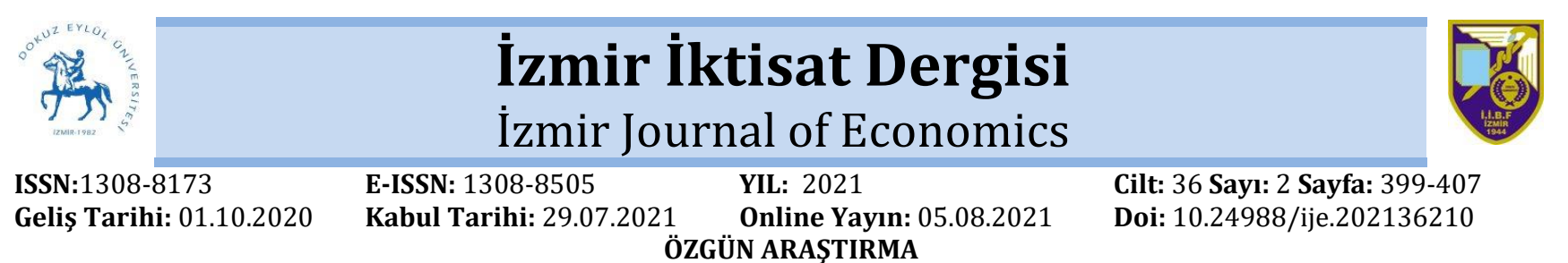

ÖZGÜN ARAŞTIRMA

\title{
Enflasyon ve İşçi Transferleri arasındaki Nedensellik İlişkisi: Türkiye Örneği
}

\begin{abstract}
Ayșe ARI ${ }^{1}$
Özet

Bu çalışmanın amacı işçi transferleri ve enflasyon arasındaki ilişkiyi Türkiye için ortaya koymaktır. Bu amaçla 1987-2019 dönemi ele alınmış ve Johansen yaklaşımı, FMOLS yöntemi ve Hacker-Hatemi (2006) nedensellik testi kullanılmıştır. Johansen testi sonucuna göre, değişkenler arasında uzun dönem ilişki bulunmaktadır. FMOLS analizi bulguları ise, teoride beklenildiği gibi işçi transferlerinin enflasyonu artırdığını göstermektedir. Ayrıca, dış borçların enflasyon üzerinde pozitif etkiye sahip olduğu ancak dışa açıklık oranının istatistiksel olarak anlamlı olmadığı tespit edilmiştir. Hacker-Hatemi (2006) testi sonucu ise, işçi transferlerinden enflasyona doğru tek yönlü bir nedenselliğin varlığını göstermektedir.

Anahtar kelimeler: İş̧̧ transferleri, enflasyon, nedensellik, eşbütünleşme

Jel Kodu: E31,F22,F20

\section{The Causality Relationship between Inflation and Worker Remittances: Evidence from Turkey}

\section{Abstract}

The aim of this study is to investigate the relationship between the worker remittances and inflation for Turkey over the period 1987-2019. To this aim, Johansen approach, FMOLS method and Hacker-Hatemi (2006) causality test are used. According to the results of Johansen test, there is cointegration between the variables. The results of the analysis of FMOLS implied that remittance inflows significantly increase inflation as expected in theory. It is also found that external debt have pozitif effect on inflation while the variable openness is statistically insignificant. The results of the Hacker-Hatemi (2006) causality test displayed the existence of unidirectional causality running from worker remittance to inflation.
\end{abstract}

Keywords: Worker remittances, inflation, causality, cointegration

Jel Codes: E31,F22,F20

\section{Gİiș}

İşçi transferleri finansman sıkıntısı yaşayan gelişmekte olan ülkeler için önemli bir dış sermaye kaynağıdır. Doğrudan yabancı yatırımlar ve yardımlar gibi dış kaynaklarla karşılaştırıldığında, daha istikrarlı bir yapıya sahip olduğu görülmektedir. Bu sebeple işçi transferleri otoriteler açısından ekonomik büyümenin sağlanmasında önemli bir kaynak olarak kabul edilmektedir (Tung vd., 2015:1; Beine, 2012:844). Ayrıca, işçi transferleri, uluslararası rezervlerdeki düşüş ya da dış borçlardaki artışlar nedeniyle yatırımcıların ani çıkışlarına karşı ekonomik istikrarın sağlanmasında önemli rol üstlenmektedir
(Gupta vd., 2009:105; Beine,2012:844). İşçi transferleri uluslararası rezervler ve ödemeler dengesini olumlu etkilediğinde bu durum ülkenin kredi notunu da olumlu etkileyecek ve böylece diş borçlanma maliyetinde düşüş sağlayacaktır. Ödemeler dengesindeki iyileșme sonrasında ülke dış yükümlülüklerini yerine getirebilmek için daha iyi bir finansal pozisyona sahip olacaktır. İşçi transferleri finansal piyasalardaki likiditenin artmasını sağlayacak böylece faiz oranını düşürerek kredilerde, tüketim harcamalarında ve yatırımlarda hızlanma sağlayabilecektir (Rivera ve Tullao, 2020:307-308).

ATIF ÖNERİsí (APA): Arı, A. (2021). Enflasyon ve İşçi Transferleri arasındaki Nedensellik İlişkisi: Türkiye. İzmir İktisat Dergisi. 36(2). 399-407. Doi: 10.24988/ije.202136210

${ }^{1}$ Dr. Öğretim Üyesi, Mersin Üniversitesi, İktisadi ve İdari Bilimler Fakültesi, İktisat Bölümü,

EMAIL: ayseari@mersin.edu.tr, ORCID: 0000-0002-8485-5932. 
İșçi transferlerinin ekonomik büyüme, yoksulluk ve yatırımlar gibi makroekonomik değişkenler üzerinde olumlu katkı yapması beklenirken enflasyonu artırarak ekonomide istikrarsızlığa da yol açabilmektedir. İşçi transferleri, talep yönlü enflasyon yaratan değişkenlerden biri olarak kabul edilmekte ve enflasyonu döviz kuru, para arzı ve ödemeler dengesi gibi kanallarla etkileyebilmektedir (Roy ve Rahman, 2014:6). Ancak enflasyon ve işçi transferleri arasında karşılıklı bir etkileşim de olabilecektir. Enflasyondaki artış, sosyoekonomik sorunlar yaratarak yurtdışına gitmek isteyen işçi sayısını ve işçilerin, ülkelerindeki ailelerinin yaşam standardını korumak amacıyla gönderecekleri döviz miktarlarını etkileyebilecektir (Rivera ve Tullao, 2020:308). Bu sebeple işçi transferleri ve enflasyon arasında bir ilişkinin var olup olmadığı ve olası etkinin yönü fiyat istikrarını sağlamayı amaçlayan otoriteler için önem taşıyacaktır (Tung vd., 2015:2). Bu çalışmanın amacl da işçi transferleri ve enflasyon arasındaki ilişkiyi Türkiye için araştırmaktır. Bu doğrultuda 1987-2019 dönemi ele alınarak Johansen eşbütünleşme testi, FMOLS yöntemi ve Hacker-Hatemi (2006) nedensellik testi ile analiz edilmiştir.

\section{TÜRKIYE'DE İŞÇİ TRANSFERLERİ}

Türkiye'de 1980'li yıllarla birlikte işçi transferlerinde artış yaşanmıştır. Söz konusu yıllarda yurtdışına çıkan sayısındaki artış işçi transferlerini artırmıştır. Ülkedeki ekonomik koşullar, vasıfsız işçilerin yurtdışı tercihlerinde etkili olmuştur. Ancak birçok ülkede olduğu gibi 2000'li yılların başından itibaren işçi transferlerinde düşüş gözlenmiştir. Örneğin, 1975 yılında 1,3 milyar dolar iken 1980'de 2.07, 1990'da 3,327, 2001 'de 1.819 ve 2018 'de 1.122 milyar dolar olmuştur. İşçi transferlerinin GSYİH içerisindeki oranı ise 1980 yılında \% 3.01 iken, 2000 'de \% 1.67 ve 2010 'da \% 0.23 'e düșmüștür(Worldbank.org,2020). Bununla birlikte işçi transferlerinin resmi kayıtlara yeterince yansımadığı bu sebeple gerçek değerlerinin çok daha fazla olduğu ifade edilmektedir (Gupta vd., 2009:104).

İşçi transferlerinde son yıllarda düşüş yaşansa da Türkiye için dikkate alınması gereken bir büyüklüğe sahiptir. Türkiye'de işçi transferlerinin azalması; yurtdışına giden göçmen sayısının azalması ve daha çok vasıflı, genç ve profesyonel işçilerin yurtdışına gitmesinden kaynaklanabilmektedir (Ganeshamoorthy, 2019; Elbadawi ve Rocha, 1992:8-9). İşçi transferlerindeki değişimde belirleyici olan faktörlerden birisi de ülkedeki ekonomik koşullardır. Ülkedeki ekonomik kriz ya da daralma dönemlerinde yurtdışındaki işçilerin, ailelerinin yaşam standardını korumak amaciyla daha fazla döviz gönderdiğ teoride kabul görmektedir (Koechlin ve Leon, 2007:1; Rivera ve Tullao, 2020:311). İşçilerin ekonomik ve politik kriz dönemlerini belirsizlik olarak değerlendirip yatırım için cazip koşulların oluşmaması gerekçesiyle ülkeye gönderecekleri döviz miktarını azaltmaları da söz konusu olabilmektedir. $\mathrm{Bu}$ durumda reel GSYIH ve ekonomik büyümedeki artışların ülkeye gelen işçi transferlerini pozitif etkileyeceği ifade edilebilir (Elbadawi ve Rocha, 1992:8-9; Aydaş vd. 2004; Straubhaar ve Vadean, 2006:148-149). Türkiye için yapılan ve 1963-1982 dönemini kapsayan araştırmada otoritelerin işçi transferlerini teşvik etmek amacıyla uyguladığı yüksek faiz oranı politikalarının önemli bir etkisinin olmadığı belirlenmiştir. Çünkü Türkiye'ye gelen işçi transferlerinin ekonomik getirilere değil politik istikrara daha çok bağlı olduğu görülmüştür. $\mathrm{Bu}$ nedenle otoritelerin işçi dövizi getirenlere yüksek getiri sağlayacak faiz oranı vb. teşviklerin kayda değer bir fayda sağlamayacağı gözlenmiştir (Straubhaar ve Vadean, 2006: 148). Alper (2005) ise 1993-2003 dönemini kapsayan çalışmasında uzun dönemde faiz oranlarındaki artışla birlikte işçi transferlerinde artış tespit ederken kısa dönemde azalış olduğunu gözlemlemiştir. Elde edilen bulgular Türkiye için işçi transferlerinin uzun dönemde yatırım güdüsüyle kısa dönemde ise negatif gelir şoklarını telafi etmek 
amacıyla ailelerin tüketim alışkanlıklarını sürdürme güdüsüyle hareket etmesiyle açıklanmıştır. Kısaca işçi transferleri tek bir faktöre bağlı olmayıp işçilerin gelir düzeyleri, yatırım planları, eğitim düzeyleri, ülkenin ekonomik koşulları gibi faktörlerden etkilenmekte ve zamanla değişkenlik gösterebilmektedir (Straubhaar ve Vadean, 2006:144-145; Elbadawi ve Rocha, 1992).

\section{IŞÇI TRANSFERLERİ VE ENFLASYON}

İşçi transferlerinin geldiği ülkedeki enflasyonu genellikle artırması beklenmekte ve söz konusu artış farklı kanallar vasıtasıyla gerçekleşebilmektedir. İlk olarak, ișçi transferlerinin toplam talep üzerindeki doğrudan ve dolaylı etkisiyle enflasyonda artış ortaya çıkacaktır. İşçi transferlerini alan hane halkının geliri artacak ve hane halkı bu transferlerin bir kısmını tüketim harcaması için kullanırken bir kısmını da yatırım amacıyla kullanacaktır. İşçi transferlerinin toplam talep üzerindeki doğrudan etkisi, hane halkının dövizleri tüketim harcaması için kullanmasından kaynaklanmaktadır. Çünkü artan döviz geliri, hane halkının satın alma gücünü ve nihayetinde mal ve hizmetlere olan talebini artıracaktır. Hane halkının tüketim düzeyindeki bu yükseliş ise çarpan etkisiyle toplam talepte çok daha büyük etki yaratacaktır. Ekonominin, reel üretim düzeyinde bir gelişmenin olmadığı varsayıldığında arz edilen mal ve hizmet miktarı değişmeyecek ve böylece işçi transferleri, harcama kanalıyla talep yönlü enflasyona yol açacaktır (Iqbal, 2013:333; Tung vd.,2015:4; Narayan vd., 2011:916; Roy ve Rahman, 2014:6). İşçi transferleri yatırıma harcandığında da talep yönlü enflasyon ortaya çlkacaktır. Ancak yapılan araştırmalarda işçi transferlerinin büyük oranda dayanıklı tüketim malları ya da ev-arsa gibi ticari olmayan reel varlıklar için kullanıldığı gözlenmiştir. Örneğin Durand vd. (1996) Meksika'da işçi transferlerinin yaklaşık \% 74'ünün tüketim harcamasına, \% 10'unun yatırımlara, \% 14'ünün ev alımına ayrıldığını belirlemiştir.Gelişmekte olan ve az gelişmiş ülkelerde yurtdışına giden işçilerin çoğunluğunun dar gelirliler olduğu dikkate alındığında söz konusu ülkelerde işçi transferlerinin büyük kısmının dayanıklı tüketim malları ile sağlık ve eğitim harcaması için kullanıldığı yaygın olarak kabul görmektedir (Khan ve İslam, 2013:199; Rivera ve Tullao, 2020:309).

İşçi transferlerinin enflasyon artırıcı ikinci kanalı ise, para arzı vasitasıyla gerçekleşmektedir. Burada ülkeye giren işçi transferlerinin, ülkedeki döviz miktarı ile Merkez Bankası rezervlerini artırması ve ödemeler dengesinin fazla vermesi dikkate alınmaktadır. Merkez Bankası, artan rezervleri tam olarak sterilize edemediğinde Parasal Taban ve dolayısıyla enflasyon artacaktır (Iqbal, 2013:333; Narayan vd., 2011:916; Roy ve Rahman, 2014:6; Upadhyay ve Upadhyaya, 2011:89). İşçi transferleri üçüncü olarak, ulusal paranın değer kazanmasını sağlayarak enflasyonu etkileyebilmektedir. Ülkeye giren işçi transferleriyle birlikte Merkez Bankası rezervlerinde ve döviz arzında artıș gözlenecektir. Döviz arzındaki artışa paralel döviz talebinde bir artış gerçekleşmediğinde ulusal para değer kazanacaktır. Bu durum ülkedeki tüketiciler için artan satın alma gücü anlamına gelecek ve tüketimi artıracaktır (Iqbal, 2013:333-334). Diğer taraftan, döviz kurunun düşmesi ihracatın azalmasına sebep olarak dış ticareti olumsuz etkileyecektir. Bu durumda Merkez Bankası, kuru yükseltmek amacıyla ulusal para arzını artırma yolunu tercih edebilecektir. Para arzının artması ise Miktar Teorisine göre enflasyonu artıracaktır. Böylece her iki çerçevede işçi transferlerinin enflasyonu artırması beklenecektir (Tung vd., 2015:4). İşçi transferleri, emek piyasası kanalıyla da enflasyonist baskı ortaya koyabilecektir. Bu kanalda işçi transferlerinin hane halkının gelirini artırarak emek arzının azalmasına yol açması söz konusudur. Azalan emek arzı, ücretlerin dolayısıyla üretim maliyetlerinin artmasına sebep olacaktır. Üretim maliyetlerinin artması ise mal ve hizmetlerin fiyatlarının artması anlamına 
gelmektedir (Roy ve Rahman, 2014: 6; Narayan vd., 2011:916).

Son olarak, işçi transferleri hane halkı tarafından tamamen tüketim amacıyla kullanılmadığında tasarruf ve sermayede artış sağlayacaktır. Söz konusu tasarruflar, üretim alanına kaydırılıp yatırım için kullanıldığında ülkede üretilen mal ve hizmet miktarı artacaktır. Böylece arz miktarı artan mal ve hizmetlerin fiyatları düşecektir. Bir başka deyişle enflasyon aşağı yönde değişecektir (Iqbal, 2013:333-334). Özetle işçi transferlerinin büyük ölçüde enflasyonu artırıcı baskı yaratması beklenmekle birlikte, deflasyonist etki de ortaya çıkabilecektir.

İşçi transferlerinin enflasyonu etkilemesi beklenirken enflasyondan işçi transferlerine doğru bir etkinin görülmesi de olasıdır. $\mathrm{Bu}$ bağlamda enflasyondaki artışın ülkede ekonomik sıkıntılar yaratmasının işçi transferlerinde bir artışa yol açabilmesine işaret edilmektedir. Yurtdişına giden işçi ailelerinin genellikle vasıfsız ve dar gelirli insanlar olması sebebiyle ülkedeki enflasyon artışı, hane halkının satın alma gücünü azaltacak ve böylece sahip olduğu tüketim düzeyinin düşmesine yol açacaktır. Yurtdışındaki işçiler, ülkelerindeki ailelerinin ortalama bir tüketim seviyesini sürdürebilmesi için gönderdikleri döviz miktarını artırabilmektedir. Örneğin Rivera ve Tullao (2020) Filipinler'i araștırmıș ve ülkedeki enflasyon artışının ülkeye gelen işçi transferlerinde artışa yol açtığını belirlemiştir. Rivera ve Tullao (2020:308-311) ulaşılan bulguları, yurtdışındaki işçilerin, yükselen enflasyon karşısında ülkelerindeki ailelerinin yaşam standardını korumak için daha fazla döviz gönderme eğilimi sergilemesiyle açıklamaktadır. Ülkedeki enflasyon işçi transferlerini negatif yönde de etkileyebilecektir. Çünkü artan enflasyon, işçiler tarafından ülkede ekonomik ve politik belirsizlik ile risk ortamının hakim olduğu şeklinde değerlendirilmektedir. Özellikle yüksek ve değişken bir enflasyon oranı, yatırımlar ve dolaysıyla işçi transferleri için caydırıcı olabilecektir (Straubhaar ve Vadean, 2006:148-149; Elbadawi ve Rocha, 1992:8-9).

\section{LITERATÜR İNCELEMESİ}

İşçi transferlerinin makroekonomik değişkenler üzerindeki olası etkilerini araştıran çok sayıda çalıșma bulunmaktadır. Ancak söz konusu literatürün büyük bir kısmı işçi transferlerinin ekonomik büyüme, ödemeler dengesi ve finansal gelişme ile arasındaki ilişkiye odaklanmıştır (Örneğin; Giuliano ve Ruiz-Arranz, 2009; Nyamongo vd., 2012). İşçi transferlerinin enflasyon üzerindeki etkisini sorgulayan ampirik çalışmalar ise daha sınırlı olup, büyük ölçüde işçi transferlerinin enflasyonu artırdığg yönünde bulgulara ulaşmıştır. Ancak işçi transferlerinin enflasyonu negatif etkilediğini tespit eden örnekler de mevcuttur. Dolayısıyla literatürde bu konuda görüş birliği bulunmamaktadır.

İşçi transferlerinin enflasyonu artırdığg yönünde bulgulara ulaşan çalıșmalardan Khan ve Islam (2013), Bangladeş örneğini VAR model kullanarak 1970-2010 dönemi için analiz etmiş ve işçi transferlerindeki \% 1'lik artışın enflasyonu \% 2.48 oranında artırdığını belirlemiştir. Ancak söz konusu etkinin uzun dönem etki olduğu, kısa dönemde ise etkileşim görülmediğini belirtmiştir. VECM modeli tercih eden Roy ve Rahman (2014) ise genel enflasyon ve gıda enflasyonunu ayrı ayrı analiz etmiş ve gıda enflasyonu üzerindeki etkinin daha güçlü olduğunu belirlemiştir. Bir başka çalışmada Tung vd. (2015), 32 Asya ve Pasifik ülkelerini 1985-1932 döneminde incelemiştir. Tung vd. (2015) Panel OLS ve GMM yöntemini tercih etmiş ve işçi transferlerinin enflasyonun, Granger nedeni olduğu sonucuna ulaşmiștır. Benzer sonuçlara ulaşan Narayan vd. (2011), 54 gelişen ekonomiyi 1995-2005 yılları arasında GMM yöntemiyle analiz etmiş ve uzun dönem etkinin daha güçlü olduğunu gözlemlemiştir. 21 gelişen ekonomiyi inceleyen Ball vd. (2012) ise, panel VAR yöntemine yer vermiștir. 1980-2010 döneminin analiz edildiği çalışmada sabit ve dalgalı döviz kuru ayrımı yapılmıştır. Sabit 
döviz kuru söz konusu iken işçi transferlerinin enflasyon üzerinde artan bir etkisi gözlenirken dalgalı kurda azalan bir etki görülmüştür. İşçi transferlerinin enflasyonu artırdığı sonucuna ulaşan diğer çalışmalar arasında Cáceres ve Saca (2006), Nisar ve Tufail (2013), Islam vd. (2017), Roy ve Rahman (2014), ve Ghauri vd. (2019) yer almaktadır.

İşçi transferlerinin enflasyonu azalttığı sonucuna ulaşan çalışmalara ise Termos vd. (2013), Haderi vd. (1999) ile Khurshid vd. (2016) örnek gösterilebilir. Termos vd. (2013) Körfez İşbirliği Konseyi bölgesine odaklanarak panel OLS yöntemi ile 1972-2010 dönemini analiz etmiştir. Haderi vd. (1999) ise, Arnavutluk'ta işçi transferlerinin rezervler ve döviz kuru kanalıyla enflasyonu negatif etkilediğini belirlemiştir. Khurshid vd. (2016) ise, 58 alt ve orta gelir grubu ülkeyi Sistem GMM yöntemi kullanarak analiz etmiştir. Çalışmada işçi transferlerinin bazı ülkelerde enflasyonu pozitif etkilerken bazı ülkelerde negatif etkileyebildiğini dolayısıyla ülkeye özgü özellik sergilediğini tespit etmiştir.

\section{VERI SETI VE METODOLOJI}

$\mathrm{Bu}$ çalışmanın amacı işçi transferleri ve enflasyon arasındaki ilişkinin varlığını Türkiye için analiz etmektir. Teorik yaklaşım ve mevcut literatür dikkate alınarak aşağıdaki model kullanılmıştır (Upadhyay ve Upadhyaya, 2011; Ghauri vd., 2019);

$$
\begin{aligned}
& E N F_{t}=\alpha_{0} \text { TRANSFER }_{t}+\alpha_{1} \text { BORC }_{t}+ \\
& \alpha_{2} \text { AÇIKLIK }_{t}+\alpha_{3}+u_{t}
\end{aligned}
$$

Modelde yer alan ENF; GSYIH deflatörü olup enflasyonu temsil ederken TRANSFER; işçi transferlerini göstermektedir. Kontrol değişkeni olarak modelde yer alan BORC; d diş borçlar, $A C$ CIKLIK ise dışa açıklık oranıdır. Modelde değişkenlerin GSYİH'ya oranı ve logaritmik değerleri kullanılmıştır. Değişkenler Dünya Bankası veri sisteminden temin edilmiş olup 1987-2019 dönemini kapsamaktadır.

Çalışmada serilerin durağanlık sınaması Genelleştirilmiş Dickey Fuller (Augmented Dickey-Fuller (ADF) ve Phillips-Perron (PP) birim kök testleri ile yapılmıștır. Serilerin düzeyde birim kök içermesinin tespit edilmesi işçi transferleri ve enflasyon arasındaki uzun dönem ilişkiyi sorgulamamıza imkân tanımıştır. Eşbütünleşme ilişkisi için Johansen testine yer verilmiştir. Daha sonra uzun dönem katsayı tahmini için Phillips ve Hansen (1990) tarafından geliştirilen FMOLS yöntemi kullanılmıştır. FMOLS yöntemi küçük örneklem için tutarlı tahminler vermektedir. Ayrıca elde edilen tahminler, asimtotik olarak sapmasızdır (Phillips ve Hansen, 1990: 120). Nedensellik analizi için Hacker ve Hatemi (2006) Bootstrap nedensellik testine yer verilmiştir. Hacker ve Hatemi (2006) yönteminde, değişkenler arasındaki nedensellik ilişkinin tespiti için temelde TodaYamamoto (1995) testi uygulanmaktadır. Ancak bu yöntemde kritik değerler bootstrap tekniği ile belirlenmektedir. Böylece hata terimlerinin normal dağılmama ihtimali dikkate alınmaktadır. Hacker- Hatemi-J (2006) yaklaşımında Granger nedenselliğin olmadığını ifade eden temel hipotez aşağıdaki şekilde yazılabilir (Hacker ve Hatemi, 2006:1491);

$H_{0}: C \beta=0$

Temel hipotezin anlamlılığını sınayan WALD test istatistiği ise aşağıdaki gibi gösterilebilir (Hacker ve Hatemi, 2006:1491):

$$
(C \hat{\beta})^{\prime}\left[C\left(\left(Z^{\prime} Z\right)^{-1} \otimes S_{U}\right) C^{\prime}\right]^{-1}(C \hat{\beta})
$$

Denklemde yer alan C ; kısıtları içeren gösterge fonksiyonunu ifade ederken, vec sütün yığma operatörü olmak üzere $\beta=\operatorname{vec}(D)^{\prime}$ dir. $\otimes$; Kronecker çarpanını, $S_{u}$ ise kısıtsız VAR model için hesaplanan varyans-kovaryans matrisini göstermektedir.

\section{AMPİRİK BULGULAR}

İlk olarak değișkenlerin durağanlıkları sınanmıştır. Serilerin durağanlığını test etmek için tercih edilen ADF ve PP testi sonuçları Tablo 1'de özetlenmiştir.

Tablo 1 incelendiğinde değişkenlerin düzeyde, hem sabitli hem de sabit ve trendli modeller için birim kök içerdiği görülmektedir. Bir 
bașka deyișle, düzey değerleri için serilerin birim köklü olduğu temel hipotezi reddedilememekte, değişkenlerin 1. dereceden durağan olduğu anlaşılmaktadır. ADF ve PP birim kök testi sonuçları birbirini destekler niteliktedir. Bu sebeple değişkenler arasında Johansen eşbütünleşme testi yaparak uzun dönem ilişkiyi sorgulayabiliriz.

Tablo 1: ADF ve PP birim kök testleri

\begin{tabular}{|c|c|c|c|c|}
\hline & \multicolumn{4}{|c|}{ PP Birim Kök Testi } \\
\hline \multirow[t]{2}{*}{ Değişken } & \multicolumn{2}{|c|}{ Sabitli Model } & \multicolumn{2}{|c|}{ Sabit ve Trendli Model } \\
\hline & Düzey & 1.Fark & Düzey & 1.Fark \\
\hline ENF & $\begin{array}{l}- \\
0.93375 \\
(0.7641)\end{array}$ & $\begin{array}{l}-6.8393^{*} \\
(0.000)\end{array}$ & $\begin{array}{l}-2.1884 \\
(0.4796)\end{array}$ & $\begin{array}{l}-6.75527^{*} \\
(0.000)\end{array}$ \\
\hline BORÇ & $\begin{array}{l}- \\
2.20895 \\
(0.2071)\end{array}$ & $\begin{array}{l}-5.0786^{*} \\
(0.0003)\end{array}$ & $\begin{array}{l}-2.6451 \\
(0.2644)\end{array}$ & $\begin{array}{l}-5.33846^{*} \\
(0.0007)\end{array}$ \\
\hline AÇIKLIK & $\begin{array}{l}- \\
0.96844 \\
(0.7524)\end{array}$ & $\begin{array}{l}-5.9759^{*} \\
(0.000)\end{array}$ & $\begin{array}{l}2.5191 \\
(0.3174)\end{array}$ & $\begin{array}{l}-5.60764^{*} \\
(0.0004)\end{array}$ \\
\hline \multirow[t]{4}{*}{ TRANSFER } & $\begin{array}{l}- \\
0.43457 \\
(0.8912)\end{array}$ & $\begin{array}{l}-3.9893^{*} \\
(0.0044)\end{array}$ & $\begin{array}{l}-2.3277 \\
(0.4080)\end{array}$ & $\begin{array}{l}-3.9363^{* *} \\
(0.0223)\end{array}$ \\
\hline & \multicolumn{4}{|c|}{ ADF Birim Kök Testi } \\
\hline & \multicolumn{2}{|c|}{ Sabitli Model } & \multicolumn{2}{|c|}{ Sabit ve Trendli Model } \\
\hline & Düzey & 1.Fark & Düzey & 1.Fark \\
\hline ENF & $\begin{array}{l}0.994 \\
(0.7433) \\
\end{array}$ & $\begin{array}{l}-6.866^{*} \\
(0.0000) \\
\end{array}$ & $\begin{array}{l}-2.0631 \\
(0.5458) \\
\end{array}$ & $\begin{array}{l}-6.766^{*} \\
(0.000) \\
\end{array}$ \\
\hline BORÇ & $\begin{array}{l}-1.9764 \\
(0.2951) \\
\end{array}$ & $\begin{array}{l}-4.951 \\
(0.000)^{*}\end{array}$ & $\begin{array}{l}-2.4225 \\
0.3618 \\
\end{array}$ & $\begin{array}{l}-4.993^{*} \\
(0.0018)\end{array}$ \\
\hline AÇIKLIK & $\begin{array}{l}-1.4376 \\
(0.5515)\end{array}$ & $\begin{array}{l}-4.870 \\
(0.000)^{*}\end{array}$ & $\begin{array}{l}-3.0290 \\
0.1419\end{array}$ & $\begin{array}{l}-4.778^{*} \\
(0.0032)\end{array}$ \\
\hline TRANSFER & $\begin{array}{l}-0.5036 \\
(0.8774)\end{array}$ & $\begin{array}{l}-4.163 \\
(0.002)^{*}\end{array}$ & $\begin{array}{l}-3.0130 \\
(0.1449)\end{array}$ & $\begin{array}{l}-4.06^{* *} \\
(0.0169)\end{array}$ \\
\hline
\end{tabular}

Not: Parantez içerisindeki değerler, olasılık değerleridir. ${ }^{* * ;} \%$ 5, *; \% 1 anlamlılık düzeyi için 1.dereceden durağanlığı göstermektedir.

Tablo 2: Johansen eşbütünleşme testi sonuçları

\begin{tabular}{|c|c|c|c|}
\hline $\begin{array}{l}\text { Maksimum } \\
\text { rank }\end{array}$ & Özdeğer & İz istatistiği & $\begin{array}{l}\text { Kritik değer } \\
\% 5 \\
\end{array}$ \\
\hline $0^{*}$ & 0.788212 & 73.08227 & 47.85613 \\
\hline 1 & 0.487422 & 29.62150 & 29.79707 \\
\hline 2 & 0.322436 & 10.90902 & 15.49471 \\
\hline \multirow[t]{2}{*}{3} & 0.000356 & 0.009982 & 3.841466 \\
\hline & Özdeğer & $\begin{array}{l}\text { Maksimum } \\
\text { özdeğer } \\
\text { istatistiği }\end{array}$ & $\begin{array}{l}\text { Kritik değer } \\
\% 5\end{array}$ \\
\hline $0^{*}$ & 0.788212 & 43.46077 & 27.58434 \\
\hline 1 & 0.487422 & 18.71248 & 21.13162 \\
\hline 2 & 0.322436 & 10.89904 & 14.26460 \\
\hline 3 & 0.000356 & 0.009982 & 3.841466 \\
\hline
\end{tabular}

Tablo 2'de gösterilen Johansen testi ve iz istatistikleri sonuçlarına göre, eşbütünleşmenin olmadığını ifade eden boş hipotez reddedilmiştir. Böylece \% 5 anlamlılık düzeyi için değișkenler arasında eșbütünleșme ilişkisinin olduğu sonucuna ulaşılmıştır. Özdeğer istatistikleri de, iz istatistikleri ile aynı doğrultuda bulgular sunmaktadır. Bu durumda değişkenler arasında uzun dönem ilişkinin varlığı ortaya çıkmaktadır. Uzun dönem katsayı tahminleri için FMOLS tahmincilerine başvurabiliriz.

Tablo 3: FMOLS sonuçları

\begin{tabular}{|l|l|l|l|}
\hline Değişkenler & Katsayı & $\begin{array}{l}\text { Test } \\
\text { istatistiği }\end{array}$ & Prob \\
\hline TRANSFER & 0.954518 & 8.911923 & 0.0000 \\
\hline BORÇ & 2.117912 & 3.106246 & 0.0043 \\
\hline AÇIKLIK & -0.064389 & -0.082497 & 0.9348 \\
\hline C & 2.482167 & 1.731439 & 0.0944 \\
\hline
\end{tabular}

FMOLS sonuçlarına göre işçi transferleri ve dış borç değișkenleri, enflasyonu belirlemede istatistiksel olarak anlamlıdır. İşçi transferlerindeki \% 1'lik artış, enflasyon oranını \%' de 0.95 oranında artırmaktadır. Bu bulgulara göre, Türkiye'ye gelen işçi transferlerinin teorik yaklaşımla uyum gösterecek şekilde enflasyonu artırıcı etki yaptığı sonucuna ulaşılmaktadır. Dış borçlardaki \% 1 oranındaki artış ise, enflasyonu yaklaşık \% 2.11 oranında artırırken dışa açıklık oranı, istatistiksel olarak anlamlı bulunmamıştır.

Tablo 4: Hacker ve Hatemi (2006) bootstrap nedensellik testi sonuçları

\begin{tabular}{|c|c|c|c|c|}
\hline \multirow[t]{2}{*}{ Temel Hipotez } & \multirow{2}{*}{$\begin{array}{l}\text { MWALD } \\
\text { istatistiği }\end{array}$} & \multicolumn{3}{|c|}{ Bootstrap kritik değerleri } \\
\hline & & $\% 1$ & $\% 5$ & \%10 \\
\hline TRANSFER ENF & $3.554^{*}$ & 8.237 & 4.656 & 3.126 \\
\hline ENFÆTRANSFER & 0.032 & 7.618 & 4.303 & 2.981 \\
\hline ENF $\nRightarrow A C ̧ I K L I K$ & 2.582 & 7.937 & 4.364 & 2.956 \\
\hline AÇIKLIK $\nRightarrow E N F$ & 1.082 & 8.010 & 4.273 & 2.939 \\
\hline BORÇ‡ENF & 1.371 & 7.623 & 4.242 & 3.007 \\
\hline ENFÆBORÇ & 0.389 & 8.617 & 4.500 & 3.010 \\
\hline
\end{tabular}

Not: *; \% 10 anlamlılık düzeyini ifade etmektedir

Hacker ve Hatemi (2006) bootstrap nedensellik testinden elde edilen sonuçlar ise Tablo 5'te özetlenmiştir. Ulaşılan sonuçlara göre, işçi transferlerinin enflasyonun Granger nedeni olmadığını ifade eden temel hipotez reddedilmektedir. Bir başka deyişle işçi 
transferlerinden enflasyon oranına doğru tek yönlü bir nedensellik bulunmaktadır. Söz konusu nedensellik ilişkisi \% 10 anlamlılık düzeyinde geçerlidir. Enflasyondan işçi transferlerine doğru bir nedensellik görülmemektedir. Modelde yer alan diğer değişkenler arasında ise bir nedenselliğe rastlanmamıștır.

\section{SONUÇ}

İşçi transferleri, toplam talep, para arzı ve döviz kuru kanallariyla enflasyonu yükseltebilmektedir. Transferler ile geliri doğrudan artan hane halkı tüketimini artırarak talep yönlü enflasyona yol açabilmektedir. Artan döviz miktarı ulusal paranın değer kazanmasını sağlayarak ya da para arzını artırarak da enflasyonist baskı yaratabilmektedir. Ancak enflasyondan işçi transferlerine doğru bir etki de söz konusu olabilmektedir. Çünkü enflasyonla satın alma gücü azalan hane halkının ortalama bir tüketim düzeyi sürdürebilmesi amacıyla yurtdışındaki işçilerin gönderecekleri transferler artabilmektedir. Enflasyonu belirsizlik ortamı ve risk olarak değerlendiren işçilerin gönderdikleri döviz miktarlarını azaltabilecekleri de ifade edilmektedir. Kısaca teoride yaygın olarak işçi transferlerinden enflasyona yönelik bir etki beklenmekle birlikte enflasyondan işçi transferlerine doğru bir etki de gerçekleșebilmektedir.
$\mathrm{Bu}$ çalıșmanın amacı da ișçi transferleri ve enflasyon arasındaki ilişkiyi Türkiye için araștırmaktır. $\mathrm{Bu}$ bağlamda 1987-2019 dönemi, eşbütünleșme analizi ve nedensellik testiyle analiz edilmiştir. Johansen eşbütünleşme testi sonucunda enflasyon oranı ve işçi transferleri arasında uzun dönem ilişki tespit edilmiştir. FMOLS tahmin yöntemi bulguları ise, işçi transferlerindeki \% 1'lik artışın enflasyonu \% 0.9 oranında artırdığını ortaya koymuştur. Hacker ve Hatemi (2006) bootstrap nedensellik testi de, işçi transferlerinden enflasyona doğru tek yönlü bir nedenselliğin varlığını göstermektedir. Teorideki yaygın görüşle uyuşan bu kanıtlar doğrultusunda, fiyat istikrarını hedefleyen otoritelerin işçi transferlerini daha çok yatırım alanlarına yönlendirecek şekilde teşvik edici politikalar uygulaması gerektiğini ifade edebiliriz. Böylece işçi transferleri reel üretime katkı sağlayabilir ve deflasyonist etki görülebilir. Khan ve Islam (2013)'ın ifade ettiği gibi ișçi transferleri, yatırım amacıyla kullanıldığında yine toplam talep ve enflasyon artırıcı etkisi olacaktır. Ancak yatırımların üretimi artırıcı etkisi enflasyondaki artışı azaltacak ya da ortadan kaldırabilecektir. Özetle Türkiye'de fiyat istikrarını sağlamayı amaçlayan otoritelerin, işçi transferlerinin enflasyonist etkisi olduğunu dikkate alması ve uygulayacakları politikaları buna göre belirlemesi gerekmektedir.

\section{KAYNAKÇA}

Alper, A. M. (2005). İşçi Dövizlerini Belirleyen Makro Ekonomik Etkenler: Türkiye Örneği. Central Bank of Turkey, http://www3.tcmb.gov.tr/kutuphane/TURKC E/tezler/ahmetmuratalper.pdf.

Aydaş, O., Neyapti, B. ve Metin-Özcan, K. (2004). Determinants of Workers' Remittances: The Case of Turkey. Working Paper, Bilkent University.

Ball, C., Lopez, C. ve Reyes, J. (2012). Remittances, Inflation and Exchange Rate
Regimes in Small Open Economies. MPRA Paper, No. 39852.

Beine, M., Lodigiani, E. ve Vermeulen, R.(2012). Remittances and Financial Openness. Regional Science \& Urban Economics, 42, 844-857.

Cáceres, L. R. ve Saca, N. N. (2006). What Do Remittances Do? Analyzing the Private Remittance Transmission Mechanism in El Salvador.International Monetary Fund, No. 06(250).

Dickey, D. A. ve Fuller, W. A. (1979). Distribution of the Estimators for 
Autoregressive Time Series with A Unit Root. Journal of the American Statistical Association, 74 (366), 427-431.

Durand, J., Kandel, W., Parrado, E.A. ve Massey, D.S. (1996). International Migration and Development in Mexican Communities. Demography, 33(2), 249-264.

Elbadawi, I. A. ve Rocha, R.R. (1992). Determinants of Expatriate Workers' Remittances in North Africa and Europe. World Bank Working Paper Series, No. 1038.

Ganeshamoorthy, K. (2019). Remittances as a Determinant of Import Function: A time Series Analysis. International Journal of Commerce \& Economics, 1(2), 15-21.

Ghauri, S.P., Ahmed, R.R., Veinhardt, J., Streimikiene, D. ve Qureshi, K.S. (2019). The Effects of Remittances on Inflation (CPI and WPI) and Exchange Rate: A Case of Pakıstan.

Romanian Journal of Economic Forecasting XXII (2) 2019, 146-165.

Giuliano, P. ve Ruiz-Arranz, M. (2009). Remittances, Financial Development, and Growth. Journal of Development Economics, 90(1), 144-152.

Gupta, S., Pattillo, C.A. ve Wagh, S. (2009). Effect of Remittances on Poverty and Financial Development in Sub-Saharan Africa. World Development, 37(1), 104-115.

Hacker, R. S. ve Hatemi-J, A. (2006). Tests for Causality between Integrated Variables Using Asymptotic and Bootstrap Distributions: Theory and Application. Applied Economics, 38(13), 1489-1500.

Haderi, S., Papapanagos, H., Sanfey, P. ve Talka, M. (1999). Inflation and Stabilisation in Albania. Post-Communist Economies, 11(1), 127-141.

Hansen, B.E. ve Phillips, P.C.B. (1990). Estimation and Inference in Models of Cointegration: A Simulation Study. Advances in Econometrics, 8, 225-248.

Iqbal, J., Nosheen, M. ve Javed, A. (2013). The Nexus between Foreign Remittances and
Inflation: Evidence from Pakistan. Pakistan Journal of Social Sciences (PJSS), 33(2), 331342.

Khan, Z. S. ve Islam, S. (2013). The Effects of Remittances on Inflation: Evidence from Bangladesh. Journal of Economics \& Business Research, 19(2), 198-208.

Koechlin, V. ve Leon, G. (2007). International Remittances and Income Inequality: An Empirical Investigation. Journal of Economic Policy Reform, 10(2), 123-141.

Khurshid, A., Kedong, Y., Calin, A. C. ve Popovici, O. C. (2016). Do Remittances Hurt Domestic Prices? New Evidence from Low, Lower-Middle and Middle-Income Groups. Romanian Journal of Economic Forecasting, XIX (4), 95-114.

Lopez, H., Molina, L. ve Bussolo, M. (2007). Remittances and the Real Exchange Rate. World Bank Policy Research Working Paper WPS.

Narayan, P., Narayan, S. ve Mishra, S. (2011). Do Remittances Induce Inflation? Fresh Evidence from Developing Countries. Southern Economic Journal, 77(4), 914-933.

Nisar, A. ve Tufail, S. (2013). An Analysis of Relationship between Remittances and Inflation in Pakistan. Zagreb International Review of Economics \& Business, 16(2), 1938.

Nyamongo, E. M., Misati, R. N., Kipyegon, L. ve Ndirangu, L. (2012). Remittances, Financial Development and Economic Growth in Africa. Journal of Economic \& Business, 64(3), 240260.

Phillips, P. C. B. ve Perron, P. (1988). Testing for a Unit Root in Time Series Regression. Biometrika, 75 (2), 335-346.

Rivera, J. P. R. ve Tullao, T. S. J. (2020). Investigating the Link between Remittances and Inflation: Evidence from the Philippines. South East Asia Research, 28(3), 301-326. 
Roy, R. ve Rahman, M. M., (2014). An Empirical Analysis of Remittances- Inflation Relationship in Bangladesh: Post-Floating Exchange Rate Scenario. MPRA Paper, No. 55190.

Straubhaar, T. ve Vadean, F.P. (2006). International Migrant Remittances and their Role in Development, Part III. International Migration Outlook: Sopemi 2006 Edition, 139:161.

Termos, A., Naufal, G. ve Genc, I. (2013). Remittance Outflows and Inflation: The Case of the GCC Countries. Economic Letters, 120(1), 45-47.
Tung, L.T., Pham, T., Nhu, P.T.Q., Thanh, P.T., Anh, L.T. ve Phung, T.T.P. (2015). The Impact of Remittance Inflows on Inflation: Evidence in Asian and The Pacific Developing Countries. :18.https://www.researchgate.net/publication/ 297360908_The_impact_of_remittance_inflow s_on_inflation_Evidence_in_asian_and_the_pac ific_developing_countries/link/5b03862da6fd ccf9e4f778bc/download.

Upadhyay, M. P. ve Upadhyaya, K. (2011). Effects of Remittances on Inflation and Real Exchange Rate in South Asia. Himalayan Journal of Development and Democracy, 6, (1), 88-96. 